\title{
TRANSAMINASE ACTIVITY AFTER CODEINE ADMINISTRATION
}

Peter Adams, M.B., B.Ch., B. T. Stephens, B.Sc., and G. S. Kilpatrick, M.D., M.R.C.P.(Edin.六 From the Royal Infirmary, Cardiff, and the Institute of Pathology, Welsh National School of Medicine, Cardiff

THE quantitative and serial changes that occur in serum glutamic-oxaloacetic transaminase (SGOT) activity during the course of a myocardial infarction are well recognized. Changes in SGOT activity have been observed in other diseases such as hepatitis and pancreatitis (Wróblewski and LaDue, 1955; Chinsky, Shmagranoff and Sherry, I956) and after the administration of drugs such as chlorpromazine, pyrazinamide and opiates (quoted by Wróblewski, Ross and Gregory, 1960).

Foulk and Fleisher (1957) showed that opiates given as codeine produced quite a marked increase in SGOT activity in each of six patients who had had a cholecystectomy and who had subsequent abdominal pain. They were unable to account for this phenomenon but considered that transient biliary obstruction due to codeine-induced spasm of the bile ducts and duodenum was probably responsible. They concluded that in the interpretation of a raised SGOT activity the possible role of opiates administered in the preceding 24 hours should be considered.

In view of these findings it was decided to study experimentally the effect of codeine phosphate on the SGOT and SGPT (serum glutamic-pyruvic transaminase) activities in a number of patients.

\section{Material and Methods}

A group of I 3 patients was studied. This comprised nine male and four female patients, details of which are given in the figure.

The technique used for the estimation of both SGOT and SGPT was as described in the Sigma Technical Bulletin No. 505 after Reitman and Frankel (1957). Each patient was studied for three days. On the first day a sample of venous blood was withdrawn after breakfast at 9 a.m. and subsequent specimens were obtained at 2, 4, 8,12 and 24 hours. On the second day an intramuscular injection of sterile water $(2 \mathrm{ml}$.) was given as a control immediately after the 9 a.m. venepuncture had been made. Subsequent specimens were obtained at the same times as on the first day. On the third day the same procedurd was followed except that an intramuscular injection of codeine phosphate ( 2 gr.) was given instead of. the water. Throughout the three-day period of the test the patients took a normal diet and alf were ambulant and none was having drug therapy

\section{Results}

A total of 386 separate estimations of transaminase activity were made.

Only peak levels of the two enzyme activities are shown in the figure. Detailed study of the serial estimations of both SGOT and SGPID showed some slight variation throughout the fixst 24 hours and in only four cases was the differe between the highest and lowest value on the day more than 10 units. Neither enzyme activity bore? any constant relationship to time of day.

Following the administration of water, enzyme activity followed a pattern similar to that found ord the first day; only two of the subjects showed $\underset{\mathfrak{a}}{ }$ difference of more than ro units between the highest and lowest value for that day.

Serial enzyme activities after the administration of codeine followed a pattern closely similar to that of the first and second days.

\section{Discussion}

We have not found any evidence that the administration of an opiate such as codeine has any effect on either SGOT or SGPT activities? any difference noted being within the expected: normal variation, shown in this study over the two days before codeine was given.

SGOT and SGPT activities bear a fairlw constant relationship to each other, vary little throughout the day and bear no relation to time of day.

Only one of our patients resembled those described by Foulk and Fleischer but the marked increase in transaminase activity after codein 5 administration found by them was not demonstrated. 

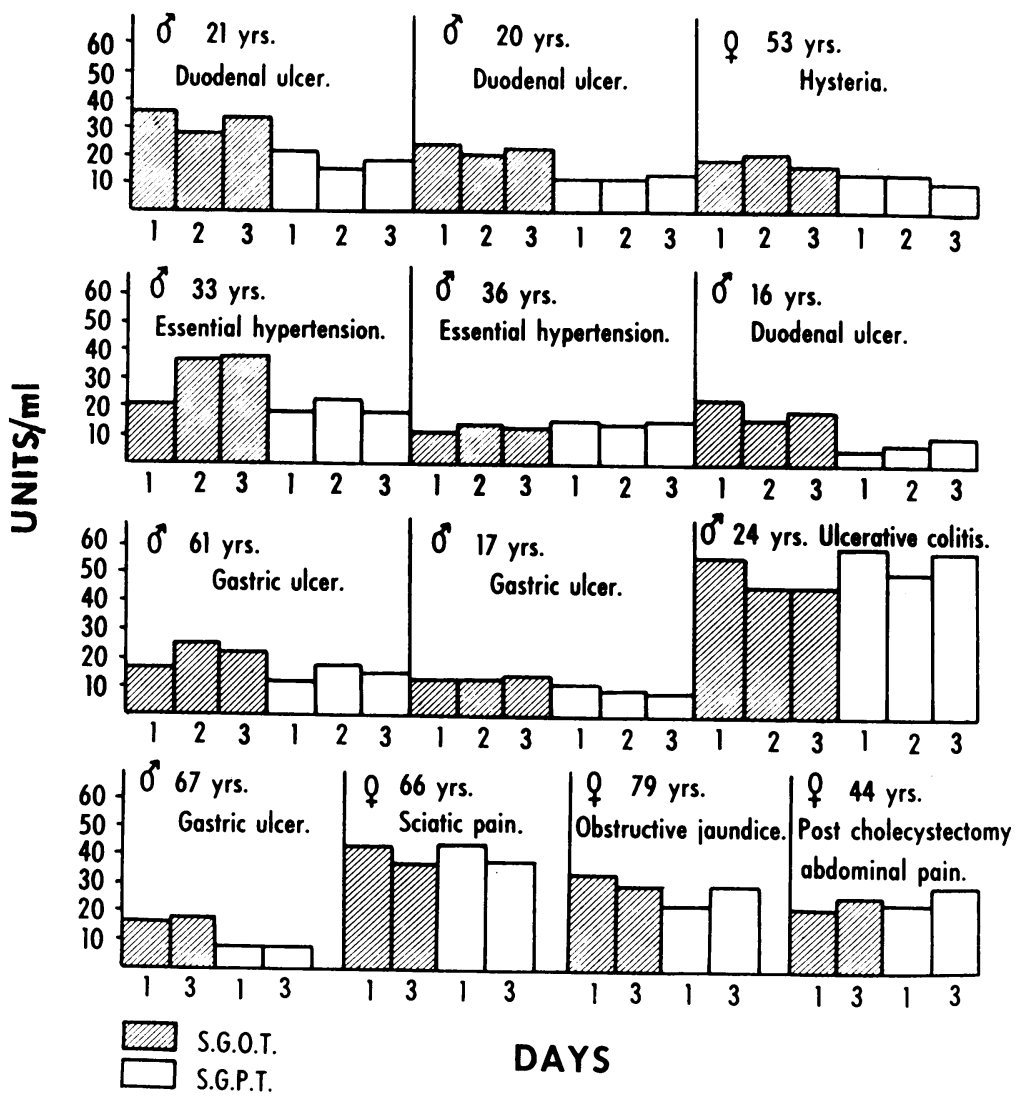

FIc. I.-Peak enzyme activities on each day of the study.

It is concluded that in general the administration of codeine has no effect on transaminase activity.

\section{Summary}

Codeine phosphate did not affect the SGOT or SGPT activities of 13 patients observed.
We are indebted to Dr. William Phillips and Professor Harold Scarborough, who allowed us to study patients admitted under their care, to Dr. J. W. Keyser for helpful advice and criticism, and to the Board of Governors of the Linited Cardiff Hospitals for support from the Endowment Fund.

\section{REFERENCES}

Chinsky, M., Shmagranoff, G. I., and Sherry, S. (i 956): Serum Transminase Activity, F. Iab. clin. Med., 47, io8 Foulk, W. T., and Fleisher, G. A. (1957): The Effect of Opiates on the Activity of Serum Transaminase, Proc. May'o Clin., 32, 405 .

Reitman, S., and Frankei, S. (i 957): A Colorimetric Method for the Determination of Serum Glutamic Oxalacetic and Glutamic Pyruvic Transaminases, Amer. F. clin. Path., 28, 56.

Wróbi.ewski, F., and LaDue, J. S. (1955): Serum Glutamic Oxalacetic Transaminase Activity as an Index of Iiver Cell Injury: A Preliminary Report, Ann. intern. Med., 43, 345 .

-, Ross, C., and Gregory, K. (1960): Isoenzymes and Myocardial Infarction, Nezi Engl. F. Med., 263, 53 . 